\title{
Cultural Heritage and Identity: The Case Study of Luxor City, Egypt
}

\author{
Mahmoud Abdou ${ }^{1}$ \\ Faculty of Architecture, Urban Planning, and Civil Engineering \\ Heritage Studies Programme
}

\begin{abstract}
This paper aims to investigate and broaden our concept of the critical relationship between cultural heritage and identity. To uncover this relationship, it is important to clearly describe the meanings attached to the concept of heritage, as the nature of the term is elastic with multiple definitions. In theory, this mutual relationship is well-established and analysed. However, in practical theory, this relationship needs further investigation to illustrate how heritage can be a crucial tool in maintaining the identities of local communities. Therefore, the research selected Luxor as the main case study due its cumulative heritage that definitely helps to discover how this heritage would shape and enhance the feeling of identity of the local community of Luxor.
\end{abstract}

Keywords: cultural heritage, identity, memorisation, sense of belonging.

\section{The Dilemma of Heritage Definition}

The world is actually full of heritage (Throsby, 2010), and heritage itself comprises multiple forms of cultural capital where it embodies different values for communities, varying from social and cultural values to historical (Benhamou, 2003). There are multiple definitions of the term 'heritage', as there are many heritage practitioners; most commentators leave the definition of heritage as broad and elastic as possible (Harvey, 2011). Heritage, according to the International Charter of Venice, is defined as 'Imbued with a message from the past'. Therefore, a common responsibility is necessary to protect and convey this heritage to future generations (ICOMOS, 1964). Meanwhile, the Convention Concerning the

\footnotetext{
1 Mahmoud Abdou got his joint Master Degree in Heritage Conservation and Site Management from Helwan University, Egypt and BTU University, Germany, in 2015. Currently, he is a Ph.D. candidate in BTU where his research focuses on the increasing role of the seeking-for-profit private sector in heritage conservation.
} 
Protection of the World Cultural and Natural Heritage defined cultural heritage as follows,

monuments: architectural works, works of monumental sculpture and painting, elements or structures of an archaeological nature, inscriptions, cave dwellings and combinations of features, which are of outstanding universal value from the point of view of history, art or science;

groups of buildings: groups of separate or connected buildings which, because of their architecture, their homogeneity or their place in the landscape, are of outstanding universal value from the point of view of history, art or science;

sites: works of man or the combined works of nature and of man, and areas including archaeological sites which are of outstanding universal value from the historical, aesthetic, ethnological or anthropological points of view (UNESCO, 1972; Edson, 2004; Ahmad, 2006).

However, Smith referred to another premise for understanding heritage in her text, Uses of Heritage, which is based on heritage itself as neither a 'thing' nor a 'site'. Rather, heritage cannot be expressed as mere material objects or buildings. Although these buildings are highly appreciated and crucial things, they are not heritage in themselves. Heritage, however, describes the practices related to these sites, but without contradicting how the sense of a physical place or site is crucial for these practices and often plays a role in them. This physical place rarely provides the full picture of what heritage can be (Smith, 2006). Graham (1994) and Ashworth et al. (2007), followed similar idea when they assumed that the significance of the heritage item arises from the interpretations, the representations created from them, and the meanings placed upon them-not from the artefact itself.

\section{The Notion of Identity}

The past is undoubtedly a crucial part of our sense of self; as Lowenthal stated: 'I was requisite to being sure that I am'. Places are not required to be impressive to be 'memorable', their significance is in the tenacity of their users rather than architecture (2015). Cuno saw identity as 'a set of currents, flowing currents, rather than a fixed place or a stable set of objects' (Cuno, 2008). Maalouf presumed identity made people different from each other (2011). Thus, rootless groups-as Lowenthal stated-are like orphaned children (2015). The notion of identity employed in this research 
refers to the ways in which identifiers-including heritage, ethnicity, nationalism, religion, language, and shared interpretations of the past-are used to shape the aspects of inclusion and exclusion that play a role in defining communities (Ashworth et al. 2007; Graham and Howard, 2008).

A number of approaches have been used to reinforce identity, such as pride for achievements in the form of rituals, memorising events, and monuments are the most popular. Memories and stories are transferred from one generation to another; thus, they become common patrimonies, legacies, and indispensable baggage that are never forgotten (Even-Zohar, 2011). Identity is not only about inclusion, but it is also about exclusion; people to identify with some, must dis-identify with others. Consequently, identity is not all about identification; rather, it also refers to similarities and differences (Anico and Peralta, 2008). Furthermore, identity is attached to terms such as 'sameness' and 'group membership', where a core point of its perception is linked to the discourse of 'other' groups with competing and even conflicting values, beliefs, and aspirations. Many pasts have transformed into a variety of identities through many heritages where only a few of which are connected to place (Ashworth et al. 2007; Graham and Howard, 2008).

\section{Cultural Heritage and Identity}

Pasts, heritages, and identities-as Ashworth et al. (2007) presumed-should be understood as plurals. This conception results from not only the multiple uses of heritage, but from, the different producers of heritage, ranging from the official-non-official, public-private, and insider-outsider perspectives, with various and different objectives related to the creation and management of heritage. Similarly, Smith stated that no individual, group, or community is attached to a singular identity. Individuals have multiple layers of identity without belonging to a certain community; additionally, a community itself may have a variety of sub-community identities. These identities need no monumental aspect to be symbolised or constituted, and even the great identities-including those of nation and class-can be seemingly shaped by the commonplace or banal (2006).

The relationship between heritage and identity is well constructed in the literature, as tangible heritage is assumed to provide a physical imagination and reality for the fragile perception of identity. Like history, heritage enhances the feelings of belonging and continuity, and tangibility representation lends these feelings an added sense of physical reality (Smith, 2006). The connectedness between the two concepts is 
distinguished by being multifaceted and changing spatially and temporally, resulting from the conceptual complexities of both terms (Graham and Howard, 2008). The use of the past to forge different conceptions of individual and group identities has considerable history, and similarly, the use of heritage remnants to construct identity, power, and authority is precisely documented (He and Zhang, 2016)

Every society or community forms a special social space. Thus, space-and the discourses linked to it-are major keys to maintaining cultural identity and transferring cultural value from one generation to another. A considerable connection is recognisable between places and memory. On an individual level, people can be deeply connected with places that are significant to their well-being. These places, whether preserved, transformed, or even destructed, can be a critical issue in maintaining a sense of identity and memorise. . On a group level, some places are significant because they boost social memory, and these places are seen as 'storehouses of memory' (Kenworthy and Shing Chow, 2003). Lowenthal argued the followings:

A place consists of everything that has happened there; it is a reservoir of memories and...a menu of possibilities... Any place that people have loved is...drenched both is belonging and in longing to belong." Some need the tangibility to feel belonging, for others, the intangible feel is sufficient. The survival of unrecognizable relics can maintain identity where there are many of the unvisited historic and symbolic places by its inhabitants, however; their existence is crucial in sustaining sense of security and continuity (2015).

A site-whether it is identified as a country or a city-is 'socialised' by its ascribed groups. Heritage, equally, is one of the major determinants of the individual features of places (Ashworth, 1994). The literature holds that heritage is a symbolic representation of the notion 'identity'. Tangible heritage or structure presents a physical representation of things from the past, embodying some of the intangible representations, including the feelings of belonging, place, self, and community (Smith, 2006). Heritage is the stimulus in a process that aims to construct and preserve a common identity. Additionally, it is the factor that typically allows the community to explore its steady anchor in the past and symbolically outlines its frames and borders. (Kocój and Gaweł, 2015). Referring to this point, Edson (2004), stated 'Things [heritage] stabilise our sense of who we are; they give a permanent shape to our views of ourselves that otherwise would quickly dissolve in the flux of consciousness'. The tendency to demonstrate memory by identifying a place is a recognised movement in all modern societies, especially after a conflict or a traumatic event. Places create important sites, which are invested with meaning and often demonstrate the 
heritage of a society, community, or individual. People can be emotionally or physically associated with these places and, in turn, maintain a sense of belonging and identity (McDowell, 2008).

\section{Methodology}

This research was part of a master's thesis submitted in 2015. The research intended to investigate to investigate the increasing role of cultural heritage in shaping and enhancing the feeling of identity and belonging in a local community. The research held in-depth interviews with 10 people from the local community of Luxor, to explain and understand how such an enriched city with significant heritage fosters a feeling of identity in its community. The samples varied from people working in tourism offices to local industries, and/or having their own businesses, such as bazars. The length of each interview was between 30-45 minutes. Content analysis was the second method used in the research with the intent to create a more interpretive and meaningful text.

\section{The Case Study of Luxor}

Luxor-also known as Thebes-is one of the richest, largest and most wellknown archaeological sites across the world. It is widely recognised by its significant ancient monuments (Fig. 1) and as one of the foremost cities of ancient Egypt, staring in the Middle Kingdom (1980-1630 B-C-E) until the end of the Roman period (Toonen et al., 2018). The city was the capital of Egypt during the New Kingdom (1550-1070 B.C.E), and the centre of the Theban warrior clans is assumed to be on the eastern bank of the Nile about 400 miles south of the current capital, Cairo (Bunson, 2002; Weeks et al., 2006).

Ancient Thebes and its necropolis are one of six Egyptian sites on the UNESCO World heritage List (WHL). This text focuses on the eastern part of the world heritage site in the city of Luxor. This eastern part includes the magnificent Luxor Temple, Karnak Temples, and Avenue of Sphinx that connects the two temples together. The world heritage site covers a large area, approximately $12.5 \mathrm{~km}^{2}$, including the buffer zone on the Eastern side and a currently populated area of about 211,000 residents (Fig. 2) (Hesham and Baller, 2018). Thebes was inscribed on the UNESCO WHL as 'the city of god Amon ${ }^{2}$ and it was the capital of Egypt during the Middle and New

\footnotetext{
${ }^{2}$ For more information about the different gods in ancient Egypt please check, Bunson (2002).
} 
Kingdom. With the temples and palaces of Karnak and Luxor and the necropolises of the Valley of the Kings and the Valley of Queens, Thebes is a striking testimony to Egyptian civilisation and its height'. The city was included on the WHL in 1979 under Criteria I, III, and VI (Fitzner et al., 2003; Bruns, 2008).

Currently, there is a publication ${ }^{3}$ available about the outstanding universal value of the site. However, the selection criteria refer to selected attributes that must be maintained. Criterion I indicates a need to 'represent a masterpiece of human creative genius', which can be recognised in Luxor as the Luxor Temple and Karnak Temples and the processional way that links them, consequently creating a historic landscape. Furthermore, Criterion III requires the site to 'bear a unique or at least exceptional testimony to a cultural tradition or to a civilisation which is living or which has disappeared'. Finally, Criterion VI argues the site must 'be directly or tangibly associated with events or living traditions, with ideas, or with beliefs, with artistic and literary works of outstanding universal significance'. This criterion can be expressed in Luxor through the excellence of the craftsmanship associated with the construction and decoration of the temples and tombs on both the east and west bank of the city (UNESCO, 2017; Hesham and Baller, 2018).

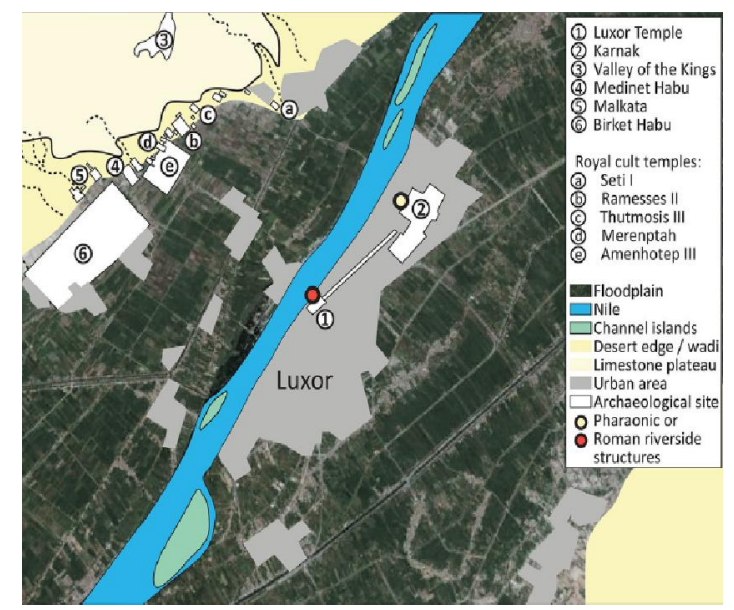

Figure 1: The western and eastern banks of Luxor City with the world heritage site on the east side. Hesham and Baller (2008).

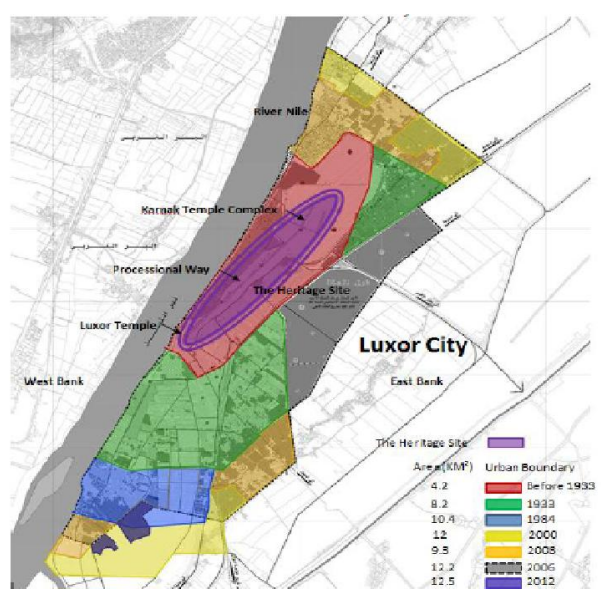

Figure 2: The location of some of the archaeological sites available in Luxor city in both eastern and western bank. Toonen et al. (2018).

\footnotetext{
${ }^{3}$ For further discussion, please check Hesham, 2018.
} 


\section{Discussion}

As briefly stated above, this research intended to investigate and understand the relationship between cultural heritage and its remarkable growing role in supporting the social identity and cohesion of the local community. Furthermore, it studied how cultural heritage can be a crucial means in shaping identity and social cohesion. This research also intended to investigate the role of the available cultural programmes in enriching the identity of the community with their inherited heritage. Finally, the research attempted to explain the different policies and legislation adopted, which are assumed to be critical tools for encouraging local community participation in the different cultural programmes and, in turn, undoubtedly optimising their identity.

Unsurprisingly, nearly all the respondents stressed the importance of living in a city enriched with a cultural heritage-such as Luxor-which undoubtedly enhances their feelings of identity and social cohesion. Interviewees indicated that the city of Luxor possesses innumerable monuments and that these inheritances are an underlying tool in strengthening the bonds of community with a location. Considering Luxor and its many monuments, the city creates and fosters the feeling of identity and cohesion amongst the community, particularly for those who are regularly associated with and involved in heritage-related activities.

As some interviewees argued, the magnificent cultural heritage available in the city has an important role in shaping and consolidating the feeling of identity amongst the local community and families by transmitting traditions and values from one generation to another, keeping them alive. These transmitted traditions are the intangible values acquired from living in Luxor, distinguishing them from other communities in Egypt. These statements agree with McDowell's argument that places comprised of important sites with highly invested processes of meanings often uncover the heritage of individuals, groups, or communities. People connect deeply with these sites, either in an emotional or physical way and, involving the concepts of belonging (or not belonging), ownership, and thus, identity. One way that identity can be linked to a place/site is experienced through the feeling of belonging to that place. It is a location where a person experiences the feeling of being at home or comfortable, as some characteristics of how a person defines himself / herself are simply reflected by specific qualities of that place. Additionally, a sense of place is 
firmly attached to the socially constructed beliefs and perceptions that individuals or groups hold about a specific location (2008). These values and traditions-transformed from one generation to another-support the argument of Smith (2006) and Ashworth et al (2007): heritage is less about tangible artefacts or intangible forms of the past, but instead the meanings related to and representations generated from them. Thus, it is the meanings that arouse cultural or economic value and reveal why artefacts, memories, and traditions have been specifically selected. One of the interviewees mentioned the following:

The city of Luxor is not a mere city like another governorate in Egypt. It has been one of the most important cities from the Pharaonic times till the current times. It was the capital of Egypt where great rulers ruled Egypt from here [Luxor] and was one of the most important religious centres in the old times. Almost all people, especially the young ones, are aware of the significance of the city resulting from its long history, starting from the Pharaonic period, and with its accumulated archaeological site.

Some interviewees also responded to the author's question about how a connection does exist between the community and the city:

Our ancestors lived here, we have grown up here, our sons and grandsons will live here too. It is the city that shaped our past and shapes our present and future. Luxor is an important part of our lives. We have not only inherited heritage sites, but also traditions, meanings, and values that have shaped our feeling of identity and belonging. The city is not only important because of its touristic and economic significance, but also since we have the feeling of belonging to here and only to here.

These statements reveal the deep relationships between heritage, place, belonging, and identity. They refer to how places play an important role in shaping and fostering the identity of people. Locations and what they include from heritage sites have a major part in increasing the feeling of belonging and pride in the people, which therefore maximise identity. This feeling of belonging and identity is generated from a continued process of events and activities that took place in that place. These events create memories that connect people to a place or city in a physical or emotional way. Regarding this point, Smith stated, that a place provokes a sense of belonging. The idea of a place constitutes a set of cultural characteristics and demonstrates where a person lives, comes from, and who he/she is. A place represents the backbone of shared experiences within the community and a physical demonstration of continuity over time (2006).

McDowell argued that without memory, the sense of identity, culture, and heritage can be lost. Thus, through remembering, we create cultures and traditions while restraining others as memories are 'conflated' and 'embellished' (2008). If we pay close attention to the quotations above, we can recognise that some specific words and expressions are used for example, Pharaonic times, a long history, the capital of Egypt, etc. From 
these expressions it is apparent that the history of the city plays a major role in shaping current feelings of belonging and identity. As the city has a long history of different political and social activities and events, it has worked on connecting people to the city. Generation after generation has witnessed cumulative traditions, meanings, and values. When such events are provoked, memories are generated, and the act of remembering comes to the surface. From this point, memories are key in consolidating the sense of belonging and identity. Smith (2006) also shared this idea when she stated that sites and cities are much more than a checklist for what they include; rather, they can be treated as 'theatres of memories'.

It is interesting that for many interviewees, the well-recognised, long oral history of the city can be considered their heritage. Almost everyone in the city can smoothly recite its history-the core of their identity-like a historian, without any exaggeration. This transmitted oral history from one generation to another significantly helps to foster and deepen the sense of belonging and identity in the local community. So, in passing on history, the acquired values and tradition can be suggested as the researcher calls them-'the real assets and acquisitions' of the local community.

It is remarkably clear that the majority of the local community in the city of Luxor is highly aware of the significant role of cultural heritage has played in shaping their own identity and the need to protect that heritage for future generations. However, they also referred to a need for a wide range of cultural programmes and activities to promote and increase awareness amongst the community about the significance of these archaeological sites, which are a major source of the economic industry in the city. One of the interviewees suddenly noted an important point that can be no longer neglected, considerably linked to the urgent need for an academic strategy to maximise awareness amongst the community about their heritage. This strategy should be inseparable from a comprehensive national strategy to educate people about the importance of their heritage and the role it holds in reinforcing the feeling of identity. Further, he added, there should be a special focus giving to students in schools. This new generation of young people should also be able to receive a full picture of their identity by ensuring the transmission of traditions and values from the elder generation. This younger generation is more susceptible to the international movement that weakens national identity and threatens the cultural diversity of local communities.

Of course, there are some cultural programs and activities available in the city-represented in the form of events, symposiums, and galleries-that aim to increase the awareness of the local community about their heritage and 
seek to involve them in cultural programs. However, and frankly speaking, there are some struggles and constraints related to these programs and make them implemented ineffectively. For instance, they are few in number and in turn, there is no real opportunity for everyone to involve. Secondly, the dates of these cultural programs are inappropriate since they mainly take place during the studying times of students which in turn, offers no great benefits for students to participate. Thirdly, the participation in these cultural activities is almost restricted and limited to specific figures who are directly associated with archaeology due to their position.

From these statements cultural programmes face major challenges that leave them unable to deliver their message at the expected and necessary level. Consequently, the competent authorities should consider the importance of these cultural programmes in increasing the awareness of heritage. The cultural programmes particularly when they feature an efficient implementation can become a major vehicle for strongly associating the local communities with their heritage and, consequently, reinforcing their own identity. A respondent indicated that some of these cultural activities are often offered by the 'palace of culture and the library of family', which hold a remarkable role in increasing awareness amongst the local community about their culture heritage, their identity associated with the place/city, the inherited traditions and values related to their association with that heritage, and the need to protect and transform this cultural heritage to the next generation. The availability of some workshops and events, especially for young people, is an urgent need for increasing the awareness of new generations about the city. However, these workshops and events should be offered on a regular and adequate schedule to match with many different people's schedules.

These awareness programmes are important for the present and future alike as we face the growing danger to the feeling of identity and belonging, resulting from the increasing tourism industry in the city. Lie et al. reasoned that cultural commercialisation has been diffused globally, and it threatens national culture and history of humanity (2010). Therefore, the continued implementation of cultural events and workshops is a critical tool in preserving the oral history and identity of people, which are vulnerable to cultural commercialisation and can be easily lost without conscious preservation. The local community of Luxor should be involved in cultural events and activities regularly, as without real involvement and empowerment, these activities could not deliver their messages effectively. These workshops should teach people about the notion of heritage, in forms not limited to the heritage sites and buildings, but also the intangible forms that provide the material ones meaning and a fuller picture. Further, the workshops should illustrate the transmitted traditions and values, establishing tools to preserve and transmit them to the new generation. 
Finally, these workshops must develop strategies to face cultural commercialisation resulting from increasing tourism in the city.

The degree of significance and awareness amongst the community about their heritage was clearly recognisable during the political instability in the state of Egypt in 2011. An interviewee stressed the critical point when clarifying to what extent this heritage is important to the community. $\mathrm{He}$ stated the following:

Almost all the governorates of Egypt have archaeological sites, however; none of them look like those belonging to the city of Luxor. Moreover, almost nobody appreciates the cultural heritage existed in Luxor as its local community does. During the revolution of 2010 Egypt was politically unstable and this time was a tough situation to the local community of Luxor who showed what their cultural heritage means to them and to what degree it is significant to them. These archaeological sites are not just mere stones rather; they proudly refer to the history of the city being the capital of Egypt during the Pharaonic times. The local community of Luxor during that revolution featured with hazardous political and security situations protected these archaeological sites when they shaped human chains to protect them from any potential destruction.

It is also true that other cities formed human chains during the political instability in Egypt to preserve the heritage sites Cairo especially witnessed large human chains to protect the Egyptian museum. However, it is unfair to compare Cairo-with its unlimited resources and awareness programmesto such small yet important city like Luxor. Instead, it is necessary to note that big cities like Cairo have well designed programmes to educate people about the importance of these heritage sites. So, when people in Luxor formed human chains to protect their sites, it was not an innate or accidental action; it was totally a conscious one. These conscious actions regarding the significance of heritage sites does not appear unexpectedly; rather, they emerge and evolve from the transmitted oral history of the city and the accumulated and new values and traditions. People gain values and traditions from elder generations while, they experience new traditions by living in Luxor themselves.

\section{Conclusion}

This paper attempts to discover the reciprocal relationship between two elastic concepts-heritage and identity-while the changing nature and borders of heritage have increased the complexity of the two notions. The 
relationships between heritage and identity seem to be well established in that when heritage is found, identity can be shaped and vice versa. Heritage and identity cannot be addressed separately from other aspects. However there are some notions for example, place, memory, and history that are underlying tools in understanding the nature of the two concepts. As Smith argued heritage has the ability to provide human existence with meanings by transmitting the ideas of imperishable values thorough continued lineages that undoubtedly maintain identity (2006). Commonly, people who live in a heritage-rich city or a place are able to experience a sense of belonging and, consequently, identity through their connectedness with the history and memory around them. As McDowell stated memories-with all their typologies-are linked to a place making the cultural environment fundamental to understanding the different meanings and relationships they constitute. Therefore, cultural heritage provokes our memories and maintains our connectedness with a city or place. Commemorating and remembering the past is a significant part of the present for various reasons. In addition to being strongly and undeniably linked to our sense of identity, it is also assumed to be an inherent part of heritagisation, as we remember our past according to our needed desires and aspirations (2008).

In light of this research, heritage holds a fundamental role in shaping the identity of the local community of Luxor by stressing their pride for living in such a city and conveying the different inherited social values and traditions to the next generation, which undoubtedly strengthens the feeling of identity and its continuity. However, this identity-as Graham and Howard perceived-is linked to 'a sense of time'; thus it is unsecured by a lifelong guarantee (2008). A stone that shapes an element of a heritage building can be a mere stone for some people, creating architectural or aesthetic value. However, this stone can be highly significant to other people according to their interpretations. These interpretations and the oral history of a heritage site increase the sense of identity and belonging by provoking memories and events. Memory and oral history are key facets in enhancing the sense of identity and belonging, not just the heritage assets. Considering that a heritage site/place can be unconsciously destroyed by human or nature, oral history and remembrance are efficient tools with the capacity to transmit the significance of a place and its attached knowledge and values. These in turn, shape and strengthen identity. Consequently, heritage and identity are two notions in a circle full of other concepts. If we do not preserve our oral history and memory, identity can be threatened by other global phenomenon that decrease cultural diversity between people around the world or bring different traditions and values-for example, the tourism movement.

Considering the negative effects of cultural commercialisation, it is important that the city witnesses a number of events and workshops on 
regular dates, increasing the feeling of identity and belonging of the local community. The cultural commercialisation process can be one of the most dangerous phenomenon affecting the firm values and traditions of younger generations. Therefore, effective initiatives should be directed to ensure vulnerable traditions are preserved. Workshops would be more beneficial if they took place during the summer vacation, when many young people have free time to participate. Participants should also be given adequate space for discussion and brainstorming strategies to increase awareness and address cultural commercialization. The role of competent authorities is critical in supporting these activities, ensuring they occur on a regular basis and all people are involved. Some initiatives can handle oral history and story-telling about the traditions and values of the city with the intention of educating people-especially, young people and students-on their city.

\section{Bibliography}

hmad, Y. (2006). The scope and definitions of heritage: from tangible to intangible. International journal of heritage studies, 12(3), 292300 .

nico, M. (2008). Representing identities at local municipal museums: cultural forums or identity bunkers? In Heritage and Identity (pp. 7587). Routledge.

nico, M., and Peralta, E. (Eds.). (2008). Heritage and identity: Engagement and demission in the contemporary world. Routledge.

shworth, G. J. (1994). From History to Heritage: From Heritage to Identity: In Search of Concepts and Models, in G. J. Ashworth, and P. J. larkham (eds.), Building a new Heritage: Tourism, Culture, and Identity in the New Europe (pp. 13-31). Routledge. London.

shworth, G. J., Graham, B. J., and Tunbridge, J. E. (eds.). (2007). Pluralising Pasts: Heritage, Identity and Place in Multicultural Societies (Vol. 3). London: Pluto Press.

unson, M. (2002). Encyclopedia of Ancient Egypt. Library of Congress. Revised Edition.

urns, G., Fronabarger, A. K., and Whitley, T. G. (2008). Predictive 
modeling of cultural resources in the Theban Necropolis, Luxor, Egypt.

uno, J. (2010). Who Owns Antiquity? Museums and the Battle over Our Ancient Heritage. Princeton University Press.

dson, G. (2004). Heritage: Pride or Passion, product or Service? International Journal of Heritage Studies, 10(4), 333-348.

ven-Zohar, I. (2011). The market of collective identities and legacy work, in R. During (ed.), Cultural heritage and identity politics. (pp. 31-37). Silk Road Research Foundation.

itzner, B., Heinrichs, K., and La Bouchardiere, D. (2003). Weathering damage on Pharaonic sandstone monuments in Luxor-Egypt. Building and Environment, 38(9-10), 1089-1103.

raham, B. J. (1994). Heritage Conservation and Revisionist Nationalism in Ireland, in G. J. Ashworth, and P. J. larkham, (eds.), Building a new Heritage: Tourism, Culture, and Identity in the New Europe (pp. 135-159). Routledge. London.

raham, B. J., and Howard, P. (Eds.). (2008). The Ashgate research companion to heritage and identity. Ashgate Publishing, Ltd.

arvey, D. C. (2001). Heritage pasts and heritage presents: Temporality, meaning and the scope of heritage studies. International journal of heritage studies, 7(4), 319-338.

e, D., and Zhang, J. (2016). Vernacular uses and cultural identity of heritage: trade of antique fragments in the Chinese porcelain capital. International Journal of Heritage Studies, 22(10), 844-856.

esham, E. S., and Baller, I. (2018). Changing Perspectives on Responsible Heritage Site Management: The Case of Luxor City, Egypt. História: Questões and Debates, 66(1), 141-165.

COMOC. (1964). International Charter for the Conservation and restoration of Monuments and Sites (The Venice Charter). Venice. Italy.

COMOS (1965). Report on the Constitutive Assembly. Warsaw. Poland.

enworthy Teather, E., and Shing Chow, C. (2003). Identity and place: 
the testament of designated heritage in Hong Kong. International Journal of Heritage Studies, 9(2), 93-115.

ocój, E., \& Gawel, Ł. (2015). Faces of identity and memory: the cultural heritage of Central and Eastern Europe (managing and case studies). Kraków: Jagiellonian University Press.

efebvre, H. (1991). The production of space. Cambridge: Blackwell.

- Li, Y., Zhao, J., and Weixi, H. (2010). Study on Cultural Commercialization and Public Consumption: The Case of China. International Journal of Asian Business and Information Management (IJABIM), l(3), 23-34.

owenthal, D. (2015). The past is a foreign country-revisited. Cambridge University Press.

aalouf, A. (2001). In the name of identity: Violence and the need to belong. Arcade Publishing.

cDowell, S. (2016). Heritage, memory and identity, in B. Graham, and P. Howard, (eds.), The Ashgate research companion to heritage and identity (pp. 37-53). Hampshire.

mith, L. (2006). Uses of heritage. Routledge.

hrosby, D. (2001). Economics and culture. Cambridge university press.

oonen, W. H., Graham, A., Pennington, B. T., Hunter, M. A., Strutt, K. D., Barker, D. S., and Emery, V. L. (2018). Holocene fluvial history of the Nile's west bank at ancient Thebes, Luxor, Egypt, and its relation with cultural dynamics and basin $\square$ wide hydroclimatic variability. Geoarchaeology, 33(3), 273-290.

NESCO (1972). Convention Concerning the Protection of the World Cultural and Natural Heritage. Paris.

NESCO (2017). Operational Guidelines for the Implementation of the World Heritage Convention. Paris.

eeks, K. R., Hetherington, N. J., and Jones, L. T. (2006). The Valley of 
the Kings, Luxor, Egypt: Site Management Masterplan. Theban Mapping Project.

-

orld Historical Cities. (2014). Administrative policy and examples of conservation of historical architecture in Luxor, Egypt: Review of the 14th World Conference of Historical Cities. Yangzhou, China.

in, R. (2003). Case Study Research Design and Methods. Third edition. SAGE Publications. 